\title{
Pengembangan Smart Air Condition Control Menggunakan Platform Blynk Berbasis Mikrokontroler ESP8266 dan Sensor DHT11
}

\author{
Ade Putera Kemala ${ }^{*}$, Muhammad Edo Syahputra ${ }^{2}$, Henry Lucky ${ }^{3}$, Said Achmad ${ }^{4}$ \\ ${ }^{1,2,3,4}$ Computer Science Department, BINUS Graduate Program - Master of Computer Science, \\ Bina Nusantara University, \\ Jakarta, Indonesia 11480 \\ ade.kemala@binus.ac.id; muhammad.syahputra002@binus.ac.id; hendry.lucky@binus.ac.id; \\ said.achmad@binus.ac.id
}

*Correspondence: ade.kemala@binus.ac.id

\begin{abstract}
Air Conditioners (AC) are increasingly used to get the room temperature as desired, starting from home use to keep the room cool and enjoyable, to specific room like server rooms or ATM which are focused on keeping the room cool in order to keep the equipment cool. The role of $A C$ is quite important to maintain room temperature, and its increasing use has led to the growing need for users to control the AC. The Internet of Things allows users to remotely control air conditioners using the gadgets used and get real time room temperature information. The $A C$ control system based on Internet of Things (IoT) utilizes an internet connection to monitor room temperature and control AC remotely. The devices used are DHT11 as a temperature sensor to get room temperature, Infrared Receiver to read the code sent by the remote $A C$, Infrared Transmitter to send commands to the $A C$ in the room, and ESP8266 as a microcontroller and a link to the internet. The IoT platform used is Blynk which has the ability to access the microcontroller from the user's gadget. The tests are running on room air conditioners such as the Panasonic CSPC18PKP series, the Panasonic CS-YN18TKP series and the Samsung AR09TGHQASINSE series. The test results showed that the room air conditioner was successfully controlled, and the room temperature was read in real time via an android smartphone.
\end{abstract}

Keywords: IoT, ESP8266, Blynk, AC

Abstrak - Air Conditioner $(A C)$ semakin banyak digunakan untuk mendapatkan suhu ruangan sesuai dengan yang diinginkan, mulai dari penggunaan di rumah untuk menjaga ruangan tetap sejuk dan dapat dinikmati, hingga penggunaan $A C$ pada ruang server atau $A T M$ yang difokuskan untuk menjaga ruangan tetap dingin demi menjaga peralatan yang digunakan. Peran $A C$ yang cukup penting untuk menjaga suhu ruangan, dan penggunaan yang semakin banyak, menyebabkan meningkatnya kebutuhan pengguna untuk mengontrol $A C$ semakin berkembang. Internet of Things memungkinkan pengguna dapat mengontrol $A C$ dari jarak jauh menggunakan gadget yang digunakan, dan mendapatkan informasi suhu ruangan secara real time. Sistem Pengatur $A C$ berbasis Internet of Things (IoT) memanfaatkan koneksi internet untuk memantau suhu ruangan dan kontrol $A C$ dari jarak jauh. Perangkat yang digunakan adalah DHT11 sebagai sensor suhu untuk mendapatkan suhu ruangan, Infrared Receiver untuk membaca kode yang dikirimkan oleh remote $A C$, Infrared Transmitter untuk mengirimkan perintah pada $A C$ yang ada di ruangan, dan ESP8266 sebagai mikrokontroller dan penghubung ke internet. Platform IoT yang digunakan adalah Blynk yang memiliki kemampuan untuk mengakses mikrokontroller dari gadget pengguna. Pengujian dilakukan pada $A C$ ruangan seperti Panasonic seri CS-PC18PKP, Panasonic seri CS-YN18TKP dan Samsung seri AR09TGHQASINSE. Hasil pengujian menunjukan $A C$ ruangan berhasil dikontrol dan suhu ruangan berhasil terbaca secara realtime melalui smartphone android.

Kata Kunci: IoT, ESP8266, Blynk, AC

\section{PENDAHULUAN}

Air Conditioner (AC) merupakan suatu teknologi yang berguna untuk mengkondisikan suhu dan kualitas udara di dalam ruangan, termasuk tingkat kelembapan dan sirkulasi udara (Danang et al., 2022). AC telah menjadi bagian dari kehidupan sehari-hari yang dibutuhkan oleh banyak orang di tempat yang beragam, seperti di perumahan, perkantoran, restoran, pusat perbelanjaan. Dengan fungsinya sebagai pengkondisi suhu, AC membuat keadaan dalam ruangan menjadi sejuk dan nyaman sehingga $\mathrm{AC}$ dapat dikatakan sebagai suatu kebutuhan yang mendasar. 
Terdapat berbagai macam jenis AC namun yang paling banyak digunakan yaitu AC konvensional dimana dibutuhkan remote infrared untuk mengontrolnya. Umumnya remote infrared memilki jarak jangkauan antara 9-10 meter (Nejakar et al., 2014). Namun dalam beberapa situasi, orang di dalam ruangan ber-AC tidak selalu mendapatkan akses ke remote AC meskipun mereka butuh untuk mengontrol AC pada ruangan mereka, contohnya pada area perkantoran dimana kebanyakan remote dipegang oleh staff seperti satpam atau office boy. Memanggil staff lain untuk mendapatkan remote AC merupakan kegiatan yang tidak efisien. Terdapat smartphone yang dapat digunakan sebagai remote AC namun tetap sulit diakses karena terbatas pada merk dan tipe tertentu sehingga sulit untuk diakses juga. Karena keadaan ini, pegawai perkantoran biasanya menggunakan pakaian penghangat seperti sweater, jaket, baju tebal. Suhu ruangan yang ideal sangat dibutuhkan untuk memastikan kenyamanan penghuni ruangan (Jani et al., 2017). Tingkat kenyamanan suhu merupakan efek pertukaran suhu antara tubuh manusia dengan lingkungan sekitarnya (Olesen et al., 2002). Seiring dengan berkembangnya teknologi, perangkat elektronik berkembang mendekati Internet of Things, yang merupakan konsep dimana setiap perangkat elektronik dapat saling terhubung, bertukar data, dan dikendalikan melalui internet. Pada tahun 2020, jumlah perangkat elektronik yang terhubung ke internet mencapai 50 milyar (Dave., 2011).

Dalam penelitian sebelumnya, telah dibuat sistem pengendali suhu dan pemantauan kelembaban udara berbasis Arduino Uno dengan sensor DHT22 (Islam et al., 2016). Penelitian lainnya yang terfokus pada konservasi energi menggunakan open source platform Zigbee untuk memonitoring penggunaan perangkat $\mathrm{AC}$ dalam ruangan (Han et al., 2011). Penelitian yang membahas mengenai pengontrolann suhu lainnya yaitu mengenai pembudidayaan jamur tiram (Syarifuddin, 2018). Penelitian ini mengembangkan alat yang dapat menyesuaikan suhu yang optimal untuk pembudidayaan jamur tiram dengan menggunakan mikrokontroler ESP8266 dan sensor DHT11. Selain itu juga terdapat kipas angin dan lampu pijar yang dihubungkan untuk mengatur suhu yang ada. Penelitian yang lebih lama membahas mengenai bagaimana membangun system Control AC otomatis berbasis Passive Infrared Receiver dan mikro controller ATmega16 (Desnanjaya et al., 2013). Sistem ini dapat mendeteksi adanya pergerakan manusia dan menyalakan AC dengan otomatis. Penelitian yang lebih baru dalam Control AC otomatis ini yaitu alat pengatur suhu berbasis mikrokontroller ATmega32 dan sensor suhu LM35 (Mochammad Haldi Widianto, 2019). Alat ini dapat mengatur level Fan pada AC sesuai dengan suhu ruangan yang dideteksi sehingga membuat suhu ruangan tidak terlalu dingin maupun panas. Namun penelitian sebelumnya terbatas pada pengembangan sisi hardware dan belum memerhatikan sisi softwarenya.

Dalam paper ini, dikembangkan Smart Air Condition Control untuk mengatasi masalah yang ada. Alat ini didesain dengan fungsi utama agar AC dapat menyala disaat suhu ruangan terlalu panas dan mati disaat suhu ruangan terlalu dingin. Dengan alat ini, pegawai tidak bergantung pada remote AC karena kontrol AC dilakukan dengan otomatis.
Paper ini disusun dengan menjelaskan pengembangan perangkat keras dan perangkat lunak dari Smart Air Condition Control. Pengembangan sistem ini mengubah AC yang sebelumnya berupa perangkat elektronik biasa menjadi perangkat elektronik yang terhubung dan dapat dikendalikan serta dimonitor melalui internet.

Sistem yang dikembangkan memanfaat platform IoT Blynk yang dapat diintegrasikan dengan aplikasi smartphone (Serikul et al., 2018). Untuk mengukur suhu dan kelembapan kami menggunakan sensor DHT11 (Kodali et al., 2016) dan untuk mengolah dan mengirim data yang didapatkan ke server, kami menggunakan modul esp8266 (Schwartz., 2016). yang sudah include di dalam NodeMCU (Parihar., 2019). Pengiriman sinyal inframerah ke perangkat AC dilakukan menggunakan LED infrared, dan respon dari AC akan dideteksi menggunakan IR receiver (Arunprakash et al., 2018).

\section{METODOLOGI PENELITIAN}

\subsection{Arsitektur Smart AC Control}

Berikut dalam Gambar 1 merupakan arsitektur simple dari alat yang dikembangkan dalam makalah ini. Secara garis besar, digunakan mikrokontroler berupa ESP8266 dan sensor DHT11 untuk mengecek suhu ruangan. IR juga disambungkan pada perangkat untuk mengirim sinyal mati atau nyala ke AC. Alat ini kemudian disambungkan dengan platform IoT berupa Blynk melalui WiFi dimana pengguna dapat mematikan dan menyalakan $\mathrm{AC}$ juga mengatur suhu batas atas dimana AC akan menyala dan suhu batas bawah dimana AC akan mati.

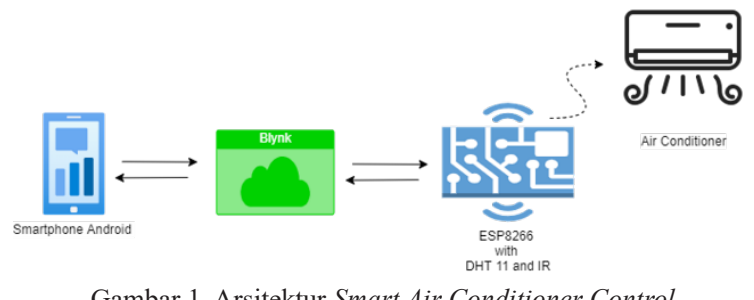

\subsection{Pengembangan Perangkat Keras}

Pada Gambar 2, dijabarkan desain skematik dari alat yang dikembangkan.

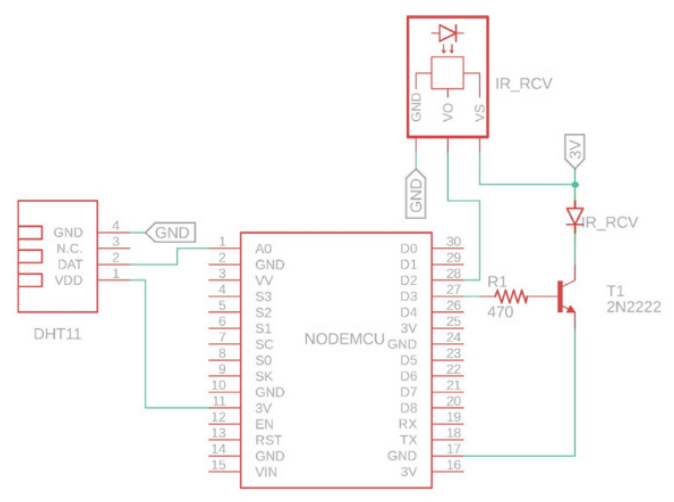

Gambar 2. Desain Skematik 
Rangkaian ini terdiri dari NodeMCU, sensor DHT11, dan IR. Adapun komponen-komponen yang digunakan:

\section{- $\quad$ NodeMCU}

Sebagai perangkat untuk mengendalikan input dari sensor dan output sinyal infrared menggunakan IR transmitter yang digunakan.

\section{- $\quad$ DHT11}

Sebagai sensor untuk mendeteksi suhu ruangan.

\section{- LED Infrared} off ke AC.

Sebagai transmitter untuk mengirimkan sinyal on/

\section{- IR Receiver}

Sebagai alat untuk membaca sinyal remote dari AC untuk direkam sehingga perangkat dapat mengirimkan sinyal tersebut ke AC.

\section{- Smartphone}

Sebagai perangkat untuk menjalankan aplikasi berbasis platform Blynk dan perangkat untuk mengontrol sistem.

\section{- Resistor}

Sebagai komponen untuk mengurangi arus pada rangkaian switch menggunakan transistor.

\section{- Transistor}

Sebagai rangkaian switch ketika trigger diberikan untuk IR transmitter melalui pin D3. Transistor yang digunakan berjenis NPN dan IR transmitter dijadikan sebagai load atau beban.

\subsection{Pengembangan Perangkat Lunak}

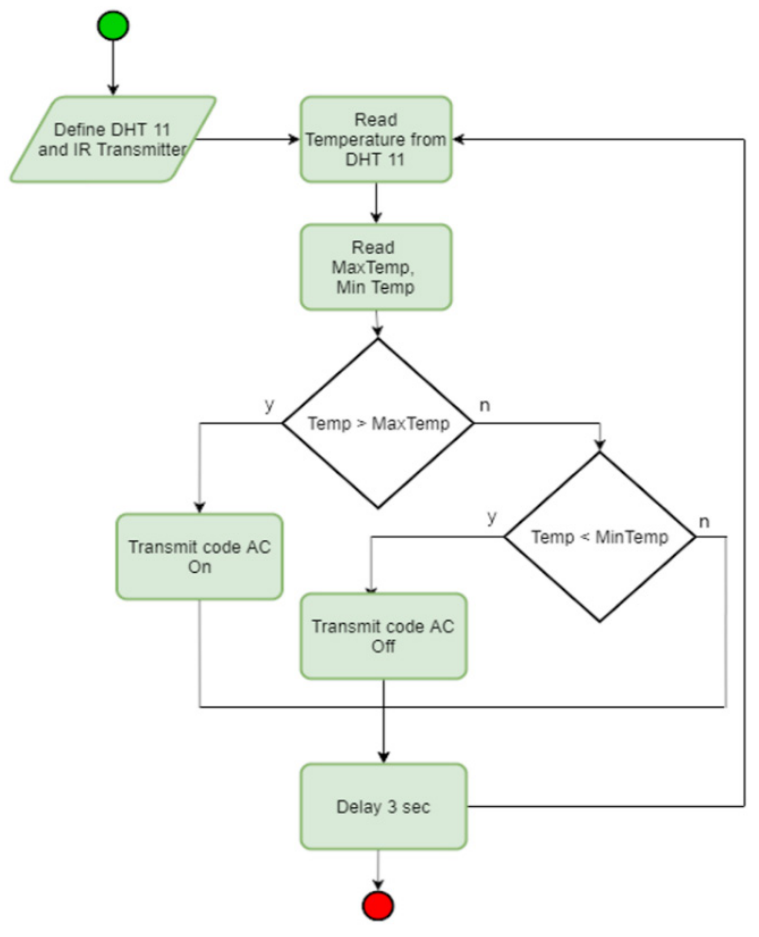

Untuk mengembangkan perangkat lunak dari Automatic Pet Feeder ini, dibutuhkan beberapa komponen utama yaitu:

\section{- $\quad$ Arduino IDE}

Arduino IDE merupakan sebuah perangkat lunak untuk menuliskan pemrograman dalam Bahasa $\mathrm{C}$ terutama untuk papan elektronik Arduino. Dalam perkembangannya bukan hanya Arduino, tetapi terdapat papan elektronik lain yang didukung oleh Arduino IDE ini. Arduino IDE ini juga digunakan untuk mengkompilasi dan menggunggah kode pemrograman ke dalam mikrokontroler yang menjadi target agar dapat berfungsi sesuai kebutuhan.

\section{- Platform Blynk}

Sebuah platform untuk aplikasi Internet of Thing (IoT) yang mempunyai layanan cloud yang gratis untuk pengguna pemula, sehingga mudah digunakan untuk kegiatan penelitian ini. Aplikasi mobile yang digunakan untuk menggendalikan sistem juga dikembangkan menggunakan platform ini.

\section{- Library}

Selain library standar Arduino IDE sistem juga dikembangkan menggunakan beberapa library tambahan diantaranya library ESP8266WiFi sebagai interface untuk menghubungkan perangkat ke jaringan wifi. Library BlynkSimpleEsp8266 sebagai interface untuk menghubungkan, mengirim dan menerima data dari server Blynk. Library DHT yang digunakan untuk mengontrol dan membaca suhu dari sensor DHT 11. Library IRsend digunakan untuk mengirim sinyal infrared menggunakan IR transmitter.

\section{HASIL DAN PEMBAHASAN}

Sebagai penggunaan sistem Smart Air Conditioner Control, digunakan aplikasi Blynk dan dilakukan langkahlangkah penyesuaian untuk menghubungkan aplikasi dengan mikrokontroler NodeMCU terlihat pada Gambar 4 dan Gambar 5. Tampilan LCD Suhu Ruangan AC.

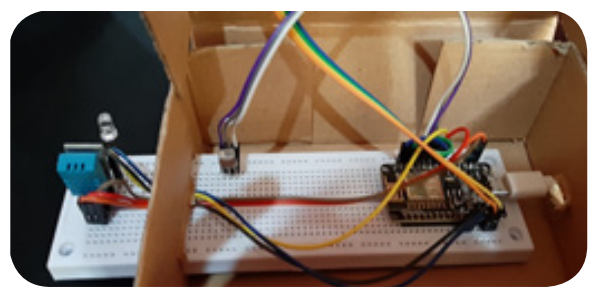

Gambar 4. Tampilan Mikrokontroler

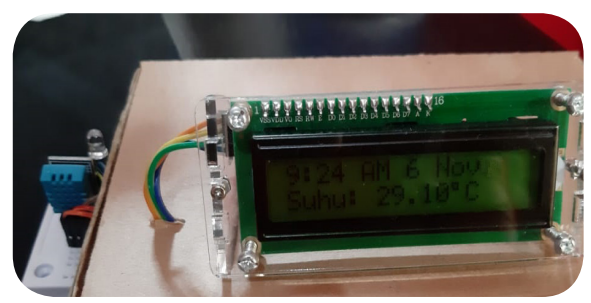

Gambar 5. Tampilan LCD Suhu Ruangan

Gambar 3. Flow Chart Sistem 


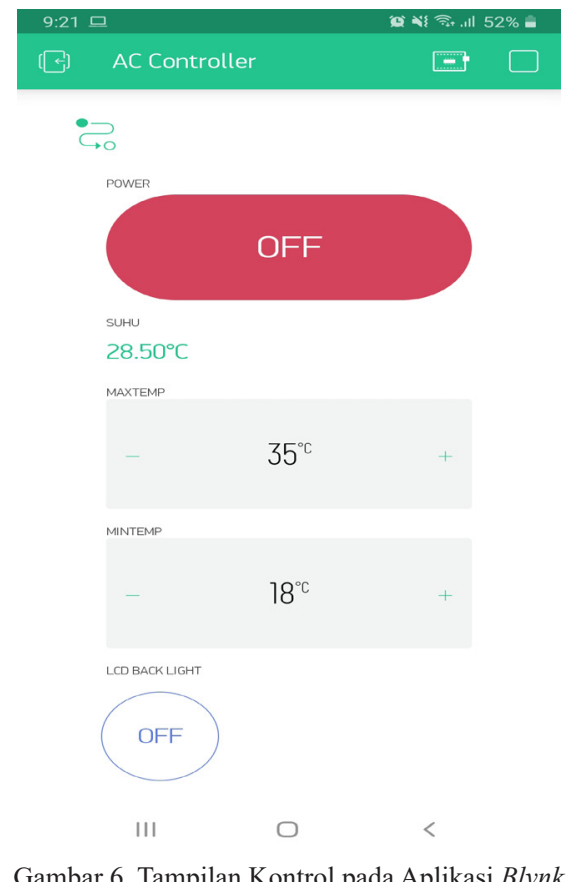

Pada Gambar 6, ditunjukan tampilan dan jenis kontrol yang digunakan dalam Blynk. Dari control yang ada, aplikasi dapat digunakan untuk menyalakan atau mematikan $\mathrm{AC}$, melihat suhu ruangan, dan mengatur suhu batas bawah dan atas. Suhu batas bawah dan batas atas menentukan range suhu yang diizinkan, apabila suhu ruangan melebihi batas atas maka AC akan dihidupkan secara otomatis dan apabila suhu ruangan lebih rendah dari suhu bawah maka $\mathrm{AC}$ akan dimatikan secara otomatis.

Untuk AC yang digunakan dalam percobaan ini terlihat dalam tabel dibawah ini,

Tabel 1. Merk dan Nomor Seri AC

\begin{tabular}{lll}
\hline No & Merk AC & \multicolumn{1}{c}{ No. Seri AC } \\
\hline \multirow{2}{*}{1} & Panasonic & CS-PC18PKP \\
\cline { 3 - 3 } & & CS-YN18TKP \\
\hline 2 & Samsung & AR09TGHQASINSE \\
\hline
\end{tabular}

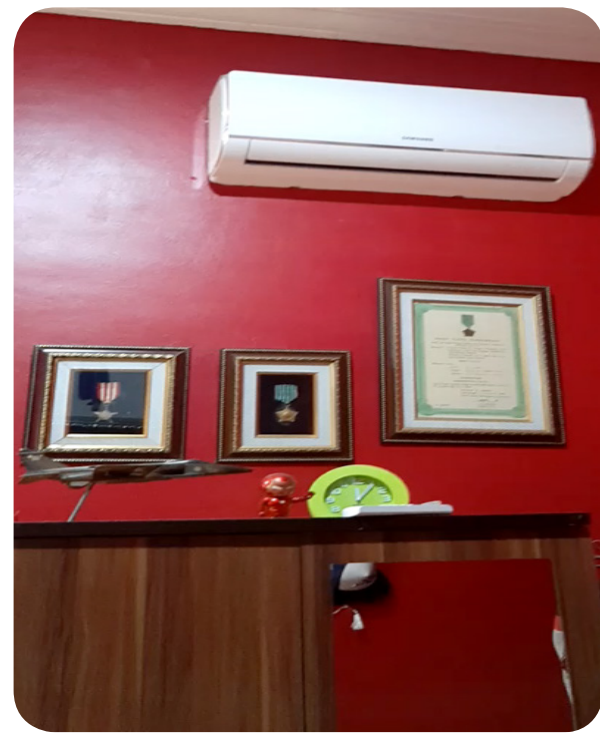

Gambar 7. Tampilan Ruangan AC

\subsection{Pembacaan dan Pengiriman Kode Sinyal dari Remote AC}

Pada pembacaan kode sinyal remote AC, dilakukan percobaan terhadap beberapa merk AC. Percobaan ini menggunakan remote AC yang ada dan diarahkan ke IR Receiver pada sistem Smart Air Conditioner Control. Berikut beberapa percobaan dapat dilihat pada Tabel 2.

\begin{tabular}{cccccc}
\multicolumn{2}{c}{ Tabel 2. Percobaan Pembacaan dan Pengiriman Sinyal Remote AC } \\
\hline \multirow{3}{*}{ No } & Merk AC & \multicolumn{2}{c}{$\begin{array}{c}\text { Sinyal yang } \\
\text { dibaca }\end{array}$} & \multicolumn{2}{c}{$\begin{array}{c}\text { Sinyal yang } \\
\text { dikirim }\end{array}$} \\
\cline { 3 - 6 } & ON & OFF & ON & OFF \\
\hline 1 & $\begin{array}{c}\text { Panasonic } \\
\text { CS-PC18PKP }\end{array}$ & Terbaca & Terbaca & Terkirim & Terkirim \\
\hline 2 & $\begin{array}{c}\text { Panasonic } \\
\text { CS-YN18TKP }\end{array}$ & Terbaca & Terbaca & Terkirim & Terkirim \\
\hline 3 & $\begin{array}{c}\text { Samsung } \\
\text { AR09TGHQASINSE }\end{array}$ & Terbaca & Terbaca & Terkirim & Terkirim
\end{tabular}

\subsection{Pengujian Sistem Smart Air Conditioner Control}

Pengujian sistem dilakukan pada 1 AC bermerk Panasonic CS-YN18TKP yang sebelumnya telah dilakukan pembacaan kode. Dalam pengujian ini, pada update suhu dan fungsi on/off terdapat jeda sebanyak 3 detik dan kondisi awal AC dalam keadaan OFF. Kami melakukan pengujian terhadap fungsi suhu atas dan suhu bawah yang berfungsi untuk menyalakan dan mematikan AC. Variabel yang disetting yaitu suhu atas dan suhu bawah pada aplikasi Blynk. Hasil pengujian dapat dilihat pada Tabel 3.

\begin{tabular}{ccccc}
\multicolumn{5}{c}{ Table 3 . Hasil Pengujian Fungsi Suhu Atas dan Suhu Bawah } \\
\hline No & $\begin{array}{c}\text { Suhu } \\
\text { Ruangan }\end{array}$ & $\begin{array}{c}\text { Suhu } \\
\text { Atas }\end{array}$ & $\begin{array}{c}\text { Suhu } \\
\text { Bawah }\end{array}$ & $\begin{array}{c}\text { Sinyal yang } \\
\text { dikirim }\end{array}$ \\
\hline 1 & 27 & 26 & 20 & ON \\
\hline 2 & 27 & 29 & 28 & OFF \\
\hline 3 & 25 & 24 & 20 & ON \\
\hline
\end{tabular}

Suhu yang ada pada Tabel 3 merupakan Celcius. Pada pengujian ini, dibuktikan bahwa fungsi pada aplikasi dapat bekerja dengan baik dalam mengatur suhu atas dan suhu bawah dengan kesesuaian kondisi AC dengan suhu yang disetting pada aplikasi.

\subsection{Pengujian Jarak pada IR Transmitter}

Pengujian sistem dilakukan pada 1 AC bermerk Panasonic CS-YN18TKP yang sebelumnya telah dilakukan pembacaan kode. Dalam pengujian ini, pada update suhu dan fungsi on/off terdapat jeda sebanyak 3 detik dan kondisi awal AC dalam keadaan OFF. Kami melakukan pengujian terhadap fungsi suhu atas dan suhu bawah yang berfungsi untuk menyalakan dan mematikan AC. Variabel yang disetting yaitu suhu atas dan suhu bawah pada aplikasi Blynk. Hasil pengujian dapat dilihat pada Tabel 4.

\begin{tabular}{cccc}
\multicolumn{3}{c}{ Table } & 4. Hasil Pengujian Jarak pada IR Transmitter \\
\hline \multirow{2}{*}{ No } & $\begin{array}{c}\text { Jarak } \\
\text { (meter) }\end{array}$ & \multicolumn{2}{c}{ Sinyal yang dikirim } \\
\cline { 3 - 4 } & 1 & ON & OFF \\
\hline 2 & 2 & Terkirim & Terkirim \\
\hline 3 & 3 & Tidak terkirim & Tidak terkirim \\
\hline
\end{tabular}


Suhu yang ada pada Tabel 2 merupakan Celcius. Pada pengujian ini, dibuktikan bahwa fungsi pada aplikasi dapat bekerja dengan baik dalam mengatur suhu atas dan suhu bawah dengan kesesuaian kondisi AC dengan suhu yang disetting pada aplikasi.

(penelitian lebih lanjut mengenai jarak dari IR)

\section{KESIMPULAN}

Penelitian ini telah berhasil merancang sistem Smart Air Conditioner Control yang dapat mengontrol AC secara otomatis sesuai suhu ruangan. Dengan alat ini, pengguna dapat mengatur AC dari jarak jauh menggunakan koneksi internet. Sensor DHT11 yang digunakan berhasil membaca suhu ruangan dan mengirimkan nilai suhu ke aplikasi Blynk melalui mikrokontroler ESP8266. Pengguna dapat mengatur suhu maksimum dan suhu minimum ruangan sehingga penggunaan $\mathrm{AC}$ dapat menyesuaikan suhu yang diinginkan melalui aplikasi Blynk, kemudian pengguna juga dapat menghidupkan atau mematikan AC secara langsung melalui tombol yang disediakan pada aplikasi. Alat yang dirancang berhasil mengontrol AC ruangan seperti Panasonic seri CS-PC18PKP, Panasonic seri CS-YN18TKP dan Samsung seri AR09TGHQASINSE. Sistem Smart Air Conditioner Control ini dapat digunakan pada ruangan khusus seperti ATM dan ruangan server yang membutuhkan sistem pemantauan suhu serta kontrol secara real time, atau fungsi yang lebih sederhana seperti pada kamar tidur atau ruangan lainnya.

\section{DAFTAR PUSTAKA}

Arunprakash, C., \& Sastry, K. R. K. (2018, January). Implementation of Air Conditioner Infrared Protocol on a Reconfigurable Hardware. In 2018 8th International Conference on Cloud Computing, Data Science \& Engineering (Confluence) (pp. 787-790). IEEE.

Danang, D., \& Toyib, M. (2022). ANALISA TROUBLE SHOOTING AIR CONDITIONER NIPPON DENSO PADA UNIT SCANIA P380 MENGGUNAKAN MICROCONTROLER. Jurnal Publikasi Teknik Informatika, 1(1), 34-44.

Desnanjaya, I. G. M. N., Giriantri, I. A. D., \& Hartati, R. S. (2013). Rancang Bangun Sistem Control Air Conditioning Automatis Berbasis Passive Infrared Receiver. Prosiding Conference on SmartGreen Technology in Electrical and Information System, C-010, 165-171. http://ojs.unud.ac.id/ index.php/prosidingcsgteis2013/article/download/7247/5496.

Evans, D. (2011). The internet of things: How the next evolution of the internet is changing everything. CISCO white paper, 1(2011), 1-11.
Han, J., Choi, C. S., \& Lee, I. (2011). More efficient home energy management system based on ZigBee communication and infrared remote controls. IEEE Transactions on Consumer Electronics, 57(1), 85-89.

Islam, H. I., Nabilah, N., Atsaurry, S. S., Saputra, D. H., Pradipta, G. M., Kurniawan, A., Syafutra, H., Irmansyah, I., \& Irzaman, I. (2016). Sistem Kendali Suhu Dan Pemantauan Kelembaban Udara Ruangan Berbasis Arduino Uno Dengan Menggunakan Sensor Dht22 Dan Passive Infrared (Pir). V(Lcd), SNF2016-CIP-119-SNF2016CIP-124. https://doi.org/10.21009/0305020123

Jani, D. B., Mishra, M., \& Sahoo, P. K. (2017). A critical review on solid desiccant-based hybrid cooling systems. International Journal of Air-conditioning and Refrigeration, 25(03), 1730002.

Kodali, R. K., \& Mahesh, K. S. (2016, December). Low cost ambient monitoring using ESP8266. In 2016 2nd International Conference on Contemporary Computing and Informatics (IC3I) (pp. 779782). IEEE.

Mochammad Haldi Widianto. (2019). Alat Pengatur Suhu Otomatis pada Ruangan Produksi Textile Spining Berbasis. 2(1), 51-58.

Nejakar, S. M., \& Pruthvi, S. (2014). Wireless infrared remote controller for multiple home appliances. International Journal of Electrical and Electronics Research, 2(1), 25-35.

Olesen, B. W., \& Parsons, K. C. (2002). Introduction to thermal comfort standards and to the proposed new version of EN ISO 7730. Energy and buildings, 34(6), 537-548.

Parihar, Y. S. (2019). Internet of Things and Nodemcu. Journal of Emerging Technologies and Innovative Research, 6(6), 1085.

Schwartz, M. (2016). Internet of Things with ESP8266. Packt Publishing Ltd.

Serikul, P., Nakpong, N., \& Nakjuatong, N. (2018, November). Smart farm monitoring via the Blynk IoT platform: case study: humidity monitoring and data recording. In 2018 16th International Conference on ICT and Knowledge Engineering (ICT\&KE) (pp. 1-6). IEEE.

Syarifuddin, A. (2018). Budidaya Jamur Tiram Berbasis Internet of Things. JURNAL TeknoSAINS, 01(01), $1-14$. 